\title{
With ‘Epidemic' Rise in OSA, Should Qualified Dentists Provide CPAP Therapy?
}

\begin{abstract}
Note from the editor: Even if you think this is an absurd title or statement, please read on.
\end{abstract}
Jean-François Masse, DMD, MSc, FACD, Diplomate, ABDSM

Editor-in-Chief Journal of Dental Sleep Medicine

Universite Laval, Quebec City, Quebec, Canada

In July of 2019, The Lancet Respiratory published an update about the prevalence of sleep apnea which estimated that 54 million people in the United States suffer from OSA. ${ }^{1}$ This estimate nearly doubled the estimates from the American Academy of Sleep Medicine in 2016. ${ }^{2}$ With the rising age of Americans, increases in comorbid conditions including diabetes, hypertension, and obesity, along with workforce shortages among physicians, nurse practitioners, and physician assistants, how can we, as dental sleep medicine experts, help alleviate this public health burden?

Phillips, Gozal and Malhotra addressed the problem in 2015, demonstrating that the number of sleep physicians is "dwindling" rapidly and severely limiting access to care in vast parts of the United States. ${ }^{3}$ As of June 30, 2018, there were 5,787 board-certified sleep medicine physicians in the United States, and more than half of those physicians practice in ten states. ${ }^{4}$

With a dearth of board-certified sleep medicine physicians throughout the country, management of sleep apnea falls to primary care physicians. Unfortunately, this is the case with most chronic conditions, and primary care physicians are simply overloaded. The AADSM began discussions with the American Academy of Family Physicians earlier this year, working on initiatives to educate family physicians about qualified dentists, oral appliance therapy and a dentist-inclusive model of care for their patients. This includes screening for OSA by qualified dentists, providing oral appliance therapy, and managing education and long-term care for patients with sleep apnea. The question is "Can we do more?" Hence the CPAP title.

It is worth considering whether qualified dentists can optimize treatment of OSA by dispensing both oral appliance therapy and CPAP. As personalized medicine and technology advances, who better to facilitate treatment with customized masks for CPAP-users than a qualified dentist? Mounting evidence demonstrates that combination therapy may be an effective option for treating sleep apnea when patients cannot tolerate CPAP and when OAT is ineffective. ${ }^{5-7}$ Certain patients are "aging out" of their appliances, while other patients experience endless issues with DME companies. Who better to aid those patients in transitioning and attaining the quality of treatment than the experienced, qualified dentist who has been managing their care for years?

Considering the above, it becomes only logical to offer a one-stop solution for patients seeking treatment for sleep apnea. Patient follow-up would become much simpler and communication with the referring physicians easier. This model would also allow physicians and dentists to work together to address the public burden of OSA in a model of care that is patient-centered, while at the same time, reducing the burden of care for physicians. Qualified dentists can then focus on what they do best - providing optimal therapeutic care to patients.

I hope this editorial will spark interest and start a conversation among us on whether this is a model of care that qualified dentists could incorporate into their practices. Whether providing CPAPs is the solution or not should not be the debate; rather, it should be how we can face the epidemic rise in OSA together - through prevention and more personalized treatment adapted to the economic and health reality of our patients.

I believe we must actively participate in the development of a new treatment model with referring physicians and other health care providers. As dentists, we made a victory of caries control - should it be the time for us to play a more integral role in the campaign to change the future of OSA management?

As Picasso said: "Others have seen what is and asked why. I have seen what could be and asked why not." Let's keep our minds open.

\section{CITATION}

Masse, JF. With 'epidemic' rise in OSA, should qualified dentists provide CPAP therapy? J Dent Sleep Med. 2019;6(4) 


\section{REFERENCES}

1. Benjafield A V, Ayas NT, Eastwood PR, et al. Estimation of the global prevalence and burden of obstructive sleep apnoea: a literature-based analysis. Lancet Respir Med. 2019;7(8):687-698. doi:10.1016/S2213-2600(19)30198-5

2. Frost \& Sullivan. Hidden Health Crisis Costing America Billions: Underdiagnosing and Undertreating Obstructive Sleep Apnea Draining Healthcare System. Darien, Am Acad Sleep Med 2016. 2016. https://aasm.org/resources/pdf/sleep-apnea-economiccrisis.pdf. Accessed July 19, 2018.

3. Phillips B, Gozal D, Malhotra A. What Is the Future of Sleep Medicine in the United States? Am J Respir Crit Care Med. 2015;192(8):915-917. doi:10.1164/rccm.201508-1544ED

4. American Board of Medical Specialties. ABMS Board Certification Report : 2018-2019. 2019. https://www.abms.org/media/257753/abms-board-certificationreport-2018-2019.pdf

5. de Vries GE, Doff MH, Hoekema A, Kerstjens HA, Wijkstra PJ. Continuous positive airway pressure and oral appliance hybrid therapy in obstructive sleep apnea: patient comfort, compliance, and preference: a pilot study. Journal of Dental Sleep Medicine 2016;3(1):5-10.
7. Liu H-W, Chen Y-J, Lai Y-C, et al. Combining MAD and CPAP as an effective strategy for treating patients with severe sleep apnea intolerant to high-pressure PAP and unresponsive to MAD. Kou YR, ed. PLoS One. 2017;12(10):e0187032. doi:10.1371/journal.pone.0187032

\section{SUBMISSION AND CORRESPONDENCE INFORMATION}

Submitted in final revised form September 22, 2019

Address correspondence to: Jean-François Masse, DDS, MSc, FACD, D.ABDSM, Professor, Universite Laval, 2780 Masson \#200, Quebec City, QC, G1P 1J6, Canada; Tel: 418871-1447; Fax: 418-871-4983; Email: jean-francois.masse@fmd.ulaval.ca 